\title{
A study of psychiatrists' concepts of mental illness
}

\author{
R. Harland ${ }^{1 *}$, E. Antonova ${ }^{2}$, G. S. Owen ${ }^{1}$, M. Broome ${ }^{3,4}$, S. Landau ${ }^{5}$, Q. Deeley ${ }^{6}$ and R. Murray ${ }^{1}$ \\ ${ }^{1}$ Division of Psychological Medicine, Institute of Psychiatry, King's College London, UK \\ ${ }^{2}$ Department of Psychology, Institute of Psychiatry, King's College London, UK \\ ${ }^{3}$ Section of Neuroimaging, Division of Psychological Medicine, Institute of Psychiatry, King's College London, UK \\ ${ }^{4}$ Health Sciences Research Institute, Warwick Medical School, University of Warwick, Coventry, UK \\ ${ }^{5}$ Department of Biostatistics, Institute of Psychiatry, King's College London, UK \\ ${ }^{6}$ Section of Brain Maturation, Institute of Psychiatry, King's College London, UK
}

Background. There are multiple models of mental illness that inform professional and lay understanding. Few studies have formally investigated psychiatrists' attitudes. We aimed to measure how a group of trainee psychiatrists understand familiar mental illnesses in terms of propositions drawn from different models.

Method. We used a questionnaire study of a sample of trainees from South London and Maudsley National Health Service (NHS) Foundation Trust designed to assess attitudes across eight models of mental illness (e.g. biological, psychodynamic) and four psychiatric disorders. Methods for analysing repeated measures and a principal components analysis (PCA) were used.

Results. No one model was endorsed by all respondents. Model endorsement varied with disorder. Attitudes to schizophrenia were expressed with the greatest conviction across models. Overall, the 'biological' model was the most strongly endorsed. The first three components of the PCA (interpreted as dimensions around which psychiatrists, as a group, understand mental illness) accounted for $56 \%$ of the variance. Each main component was classified in terms of its distinctive combination of statements from different models: PC1 33\% biological versus nonbiological; PC2 12\% 'eclectic' (combining biological, behavioural, cognitive and spiritual models); and PC3 10\% psychodynamic versus sociological.

Conclusions. Trainee psychiatrists are most committed to the biological model for schizophrenia, but in general are not exclusively committed to any one model. As a group, they organize their attitudes towards mental illness in terms of a biological/non-biological contrast, an 'eclectic' view and a psychodynamic/sociological contrast. Better understanding of how professional group membership influences attitudes may facilitate better multidisciplinary working.

Received 18 June 2008; Revised 24 October 2008; Accepted 1 November 2008; First published online 18 December 2008

Key words: Attitudes, mental disorder, mind, models, philosophy.

\section{Introduction}

Mental illness is understood in a variety of ways, both within and between psychiatric services, and in society more broadly (Clare, 1976; Engel, 1977; Sandler et al. 1992; Tyrer \& Steinberg, 2005; Deeley, 2006; Broome, 2007). For example, within psychiatry, models of mental illness include biomedical, cognitive, behavioural, psychodynamic and social perspectives (Ghaemi, 2003; Tyrer \& Steinberg, 2005). These different models inform distinct approaches to classification, explanation and treatment. They influence the focus and methods of research (for example, whether

\footnotetext{
* Address for correspondence: Dr R. Harland, Division of Psychological Medicine, PO Box 63, Institute of Psychiatry, King's College London, De Crespigny Park, London SE5 8AF, UK. (Email: r.harland@iop.kcl.ac.uk)
}

biological or social research is likely to reveal the most important causes of schizophrenia) and the significance attributed to 'symptoms' (what they are and what they mean) (Good, 1995; Kleinman, 1998). Some accounts of mental illness explicitly criticize medical or psychological models; for example, the notion that mental illness is a 'myth' based on a mistaken analogy between physical illness and psychological distress (Szasz, 1960), or the notion that psychiatric categories and practices are the product of a wider world view and reflect the interests of society at large (Foucault, 1971; Horwitz, 2002). Some psychiatrists have adopted these and similar perspectives in the movement that has come to be known as 'critical psychiatry' (Thomas \& Bracken, 2004), adding to the diversity of approaches to understanding the subject matter of psychiatry. 
Studies published previously or published while this study was in progress have attempted to measure the way that psychiatrists, medical students and other mental health workers reason about clinical material. For example, a questionnaire study found that medical students weighed both psychological and biological factors when considering aetiology and treatment of psychiatric disorders (Brog \& Guskin, 1998). A qualitative study used a 'schizophrenia vignette' to investigate implicit models used by professionals and clients in a Community Mental Health Team (CMHT) (Colombo et al. 2003). Models held by different disciplines within the CMHT informed distinct understandings of the nature of schizophrenia, the appropriateness of care alternatives, and even rights and obligations. Another vignette study investigated whether a covert mind/body dichotomy still operated in an academic department of psychiatry, despite claims that dualism had been overcome (Miresco \& Kirmayer, 2006). It was found that if a behavioural problem was seen as originating in psychological processes, rather than neurobiological causes, the patients tended to be viewed as more responsible and blameworthy for their symptoms.

However, none of these studies addressed how psychiatrists draw on a range of models (including broader cultural models) to understand different mental disorders. In the present study, we developed a questionnaire (see Appendix, available online) to measure how those working in mental health (here British trainee psychiatrists) use various models to understand clinical material. Building on research of professional attitudes conducted at the Maudsley hospital over 25 years ago (Toone et al. 1979), we aimed to provide trainee psychiatrists with a range of propositions relating to the explanation and treatment of four different mental disorders: schizophrenia, major depressive disorder (MDD), antisocial personality disorder (APD) and generalized anxiety disorder (GAD). These propositions were drawn from major explanatory models (biological, cognitive, behavioural, psychodynamic and social) and from other perspectives on mental illness (on the premise that psychiatrists may also be influenced by these alternatives). Our main hypothesis was that psychiatrists apply different models to different disorders. Our second hypothesis was that there are underlying 'dimensions' that represent broader approaches that psychiatrists, as a group, use to interpret mental illness (i.e. dimensions that relate aspects of different models, such as interpreting illness in terms of a contrast between biological and non-biological approaches). Our third hypothesis was that there would be associations between demographic variables and these dimensions.

\section{Method}

\section{Questionnaire development}

The Maudsley Attitude Questionnaire (MAQ; online Appendix) was developed between 2003 and 2004 . The first part of the questionnaire comprises items pertaining to demographic and professional background (online Appendix 1, part 1). The main body of the questionnaire (online Appendix 1, part 2) contains items formulated to probe psychiatrists' attitudes towards mental illness. The authors attempted to identify the major conceptual paradigms (models) available to those working in mental health. We included eight such models: biological, cognitive, behavioural, psychodynamic, social realist, social constructivist, nihilist, and spiritualist. Four questions were formulated to attempt to capture the essence of each model broadly in terms of aetiology, classification, research and treatment of mental disorder (see Table 1). This gave us a questionnaire with 32 questions, each of which was asked for four disorders as currently construed by DSM-IV: schizophrenia, MDD, GAD and APD. The 32 questions were subsequently assorted randomly. The answers were given on a five-point Likert scale, ranging from 1 signifying strongly disagree to 5 signifying strongly agree.

A draft of part 2 of the questionnaire was circulated to experienced clinical and research psychiatrists and psychologists with knowledge of the models included. Their comments and suggestions were used to make the questions more accurate.

\section{Pilot work}

We conducted a preliminary pilot study on 10 respondents to ensure that the questions and the format of the questionnaire were clear and understandable by the targeted respondents. The comments and criticism received were incorporated into the final version of the questionnaire.

\section{Validation study}

Initially we gave the 32 randomly assorted questions from part 2 to one senior clinician (B.T.), who did not participate in the design of the questionnaire, and asked him to assign each question to one of eight paradigms. B.T. was $100 \%$ accurate.

To ensure that the questions were identifiable as paradigmatic by trainees, we asked a subsample of participants to classify each of the 32 randomly allocated questions to one of eight paradigms after the study was completed. Their responses were scored as 'correct' or 'not correct'. The proportion of correct responses (out of 32) was considered a measure of the 
Table 1. Questionnaire items arranged by model (number of the item corresponds to the order of the item's appearance in the questionnaire)

\section{Biological}

1. The disorder results from brain dysfunction

6. The ideal classification of the disorder would be a pathophysiological one

9. The appropriate study of the disorder involves discovery of biological markers and the effects of biological interventions

17. Treatment of the disorder should be directed at underlying biological abnormalities

\section{Cognitive}

15. Maladaptive thoughts and beliefs are normally distributed in the population and it is the extreme ends of this distribution that account for the disorder

24. The disorder is nothing other than the sum of maladaptive thoughts, beliefs and behaviours

20. The study of the disorder should concentrate on understanding cognitive distortions and reasoning errors

7. The disorder should be treated by challenging and restructuring maladaptive thoughts and beliefs

\section{Behavioural}

31. The disorder results from maladapted associative learning

3. The disorder is best approached through the study of abnormal behaviour

11. Studying the associations between antecedents and consequents in patients' behaviour is the best basis for modification of the disorder

19. The behavioural problems in the disorder are best modified by associating new responses to a given stimulus

\section{Psychodynamic}

26. The disorder results from the failure to successfully complete developmental psychic stages

18. The disorder is due to unconscious factors (as defined psychodynamically)

22. The structure of the disordered psyche and its unconscious mechanisms is best understood by a study of individual cases

28. Treatment of the disorder requires resolution of disturbed early object relationships

\section{Social realist}

14. Social factors such as prejudice, poor housing and unemployment are the main causes of the disorder

2. The disorder arises as a consequence of social circumstances or conditions

5. The research into the disorder should focus on the identification of causative social factors

29. Government policies to reduce prejudice, poor housing and unemployment are the way to eradicate the disorder

\section{Social constructionist}

16. There is no universal classification of disorder, only culturally relative classifications

32. The disorder is a culturally determined construction that reflects the interests and ideology of socially dominant groups

13. The disorder can only be understood in the context of local meanings and these meanings cannot be extrapolated to universal classifications

10. Treatment of the disorder should be based on whatever folk treatments and models are accepted as appropriate by the patient and their local community

Nihilist

23. Attempts to scientifically explain the disorder have resulted in no significant knowledge

27. All classifications and 'treatments' of the disorder are myths

12. Mental health professionals have no 'expertise' of the disorder over and above anyone else

4. The management of the disorder is best left to the resources of the individual

\section{Spiritual}

8. Neglecting the spiritual or moral dimension of life leads to the disorder

30. The disorder is better understood through religious or spiritual insights

25. Consulting a spiritual authority can give a better understanding of the disorder than psychiatry

21. Adherence to religious or spiritual practice is the most effective way of treating the disorder

questionnaire's construct validity. The power calculation, based on the assumption that psychiatrists would achieve between $60 \%$ and $100 \%$ correct responses, showed that a sample of 15 psychiatrists would be sufficient to achieve an acceptable threshold for assessing construct validity of the questionnaire with the lower limit of a 95\% confidence interval (CI) exceeding $90 \%$ correct.

The validation sample consisted of trainee psychiatrists and two consultants. The observed median validation rating was $100 \%$ (range $84.4-100 \%$ ). The two models that trainees found difficulty in 
differentiating were the social constructivist and nihilist models. The other six models showed 100\% classification accuracy. This translated into a $95 \% \mathrm{CI}$ for mean construct validity between $92.3 \%$ and $98.1 \%$ (constructed by bootstrapping because more than half of the sample achieved $100 \%$ correct classification of items). Thus, we were able to confirm that our questionnaire had acceptable construct validity.

\section{Data collection}

The study was approved by the Ethical Committee of the Institute of Psychiatry, King's College London. We sampled trainee psychiatrists from the South London and the Maudsley National Health Service (NHS) Foundation Trust. We wrote to every juniorand senior-grade psychiatrist in training, sending out questionnaires by post and email. Ninety trainees were approached and 76 returned completed questionnaires, giving a response rate of $84 \%$.

\section{Statistical analysis}

To reduce the number of attitude variables, the scores for each of the four items derived from each model were summed to form a score for the model overall, based on the premise that the four items (aetiology, classification, research and treatment) within each model (biological, behavioural, cognitive, psychodynamic, social realist, social constructivist, nihilist and spiritualist) probed the same construct. This reduced the number of attitude variables from 128 to 32 per respondent (i.e. a single summed aggregate score for each of the eight models was applied to four disorders).

To address the first research question of whether psychiatrists apply different models to different disorders, a repeated-measures analysis of variance of the attitude variables was carried out. Generalized estimating equations (GEEs) for normally distributed outcomes with an exchangeable correlation structure (using standard errors that are robust against departures from this covariance structure) were used to compare mean attitude scores across disorders. A formal test of an interaction of the model by the disorder was performed to determine whether the attitude profiles varied as a function of disorder.

A principal components analysis (PCA) of the 32 attitude variables across mental disorders was carried out to identify dimensions around which psychiatrists in this sample orientate their attitudes to mental illness. A PCA is a data reduction technique applied to find a combination of variables that summarize the overall observed variation and to reduce the complexity of the data. The analysis yields as many components as there are items. The resulting principal components (PCs) are sorted in order of the amount of variability explained, the first component accounting for the largest proportion of the variance among the items, the second component accounting for the second largest proportion that is orthogonal to (independent of) the first component, and so on. The PCs are constructed as linear combinations of the original items. The contributions of the various items to a PC can be assessed in order to interpret the meaning of a PC (or dimension).

Finally, the relationship between attitude dimensions (PCA components) and demographic/professional background variables was explored using regression methods. For the demographic variables that were categorical (i.e. religious beliefs), where some of the groups had less than five cases (see Table 2), the variables were recoded such that all subgroups with less than five observations were combined into a single other variable and this new variable was used for all analyses. The data were analysed with Stata version 9 (Stata Corporation, College Station, TX, USA).

\section{Results}

\section{Demographics and professional background of the respondents}

The sample of trainee psychiatrists is described in Table 2. Of the 76 respondents, 39 (51\%) were male and $37(49 \%)$ female, with a mean age of 32 years (S.D. $=4.2$, range 25-45 years). They had spent an average of 20 years (S.D. $=3.81$ ) in education since primary school and a median of 5 years (range $0.25-21$ years) in psychiatry. One-third of the respondent psychiatrists $(34 \%)$ were apolitical, with almost as many agnostics (25\%) as there were Christians (28\%). Nine $(12 \%)$ chose psychiatry before, $33(43 \%)$ during and $34(45 \%)$ after medical school. Two (3\%) reported being in individual psychoanalysis. Sixty-three (83\%) of the respondent psychiatrists were engaged in research at the time of the study, with the largest proportion $(20 \%)$ being involved in the field of neuroimaging. There was an average of one (range 0-20) experimental peer-reviewed paper.

\section{Application of psychiatric models to mental disorders}

No statements were universally agreed with or disagreed with. The three most agreed-with statements (Likert score $>3$ ) from part 2 (models of mental illness) of the MAQ were: (1) Schizophrenia: 'The disorder results from brain dysfunction' [biological model, aetiology; 65 (86\%) of the respondents]; (2) 
Table 2. Summary of demographic and professional background of the respondents

\begin{tabular}{|c|c|c|c|}
\hline Demographic/professional background variable & $\begin{array}{l}\text { No. of } \\
\text { respondents (\%) }\end{array}$ & Mean (S.D.) & $\begin{array}{l}\text { Median } \\
\text { (range) }\end{array}$ \\
\hline Age in years & 73 & $31.85(4.20)$ & $(25-45)$ \\
\hline $\begin{array}{l}\text { Gender } \\
\text { Female } \\
\text { Male }\end{array}$ & $\begin{array}{l}76 \\
37(49) \\
39(51)\end{array}$ & - & - \\
\hline Years in education (from primary school) & 73 & $20.35(3.81)$ & - \\
\hline Number of years in psychiatry & 76 & - & $5(0.25-21)$ \\
\hline Number of years post-registration & 76 & - & $5(0-20)$ \\
\hline $\begin{array}{l}\text { Grade } \\
\text { SHO } \\
\text { SPR } \\
\text { Consultant (trainee post-CCST) }\end{array}$ & $\begin{array}{l}75 \\
34(45) \\
39(51) \\
2(3)\end{array}$ & - & - \\
\hline $\begin{array}{l}\text { Timing of decision to enter psychiatry } \\
\text { Before starting medical school } \\
\text { During medical school } \\
\text { After leaving medical school }\end{array}$ & $\begin{array}{r}76 \\
9(12) \\
33(43) \\
34(45)\end{array}$ & - & - \\
\hline $\begin{array}{l}\text { Experience of psychodynamic therapy } \\
\text { Supervised psychotherapy } \\
\text { Individual analysis } \\
\text { None }\end{array}$ & $\begin{array}{l}76 \\
71(93) \\
2(3) \\
3(4)\end{array}$ & - & - \\
\hline $\begin{array}{l}\text { Currently engaged in research } \\
\text { Yes } \\
\text { No }\end{array}$ & $\begin{array}{l}75 \\
63(83) \\
12(16)\end{array}$ & - & - \\
\hline $\begin{array}{l}\text { Area of research } \\
\text { Neuroimaging } \\
\text { Epidemiology } \\
\text { Genetics } \\
\text { Psychopharmacology } \\
\text { Psychotherapy } \\
\text { Health service } \\
\text { Cognition } \\
\text { Neuropsychology } \\
\text { Neurophysiology } \\
\text { Forensics } \\
\text { Other }\end{array}$ & $\begin{array}{l}64 \\
15(20) \\
14(18) \\
8(11) \\
6(8) \\
3(4) \\
3(4) \\
3(4) \\
3(4) \\
1(1) \\
1(1) \\
6(8)\end{array}$ & - & - \\
\hline $\begin{array}{l}\text { Number of experimental peer-reviewed papers } \\
\text { Number of case-study papers }\end{array}$ & & & $\begin{array}{l}1(0-20) \\
0(0-5)\end{array}$ \\
\hline $\begin{array}{l}\text { Religious belief } \\
\text { Agnostic } \\
\text { Atheist } \\
\text { Buddhist } \\
\text { Christian } \\
\text { Hindu } \\
\text { Jewish } \\
\text { Muslim } \\
\text { Undecided }\end{array}$ & $\begin{array}{l}75 \\
19(25) \\
20(26) \\
2(4) \\
21(28) \\
7(9) \\
2(3) \\
3(4) \\
1(1)\end{array}$ & - & - \\
\hline $\begin{array}{l}\text { Political party } \\
\text { Conservative } \\
\text { Labour } \\
\text { LibDem } \\
\text { None } \\
\text { Other }\end{array}$ & $\begin{array}{l}74 \\
4(5) \\
24(32) \\
15(20) \\
26(34) \\
5(7)\end{array}$ & - & - \\
\hline
\end{tabular}

SHO, Senior House Officer; SPR, Specialist Registrar ; CCST, certificate of completion of specialist training. 
Table 3. Descriptive statistics for the aggregate attitude scores by model and by disorder (possible range 4-20)

\begin{tabular}{lrrrr}
\hline Model & \multicolumn{1}{c}{ Schizophrenia } & $\begin{array}{l}\text { Major depressive } \\
\text { disorder }\end{array}$ & $\begin{array}{l}\text { Generalized anxiety } \\
\text { disorder }\end{array}$ & $\begin{array}{l}\text { Antisocial personality } \\
\text { disorder }\end{array}$ \\
\hline Biological & $15.60(2.89)[8-20]$ & $14.78(3.21)[8-20]$ & $13.49(3.04)[6-20]$ & $11.41(3.18)[6-20]$ \\
Behavioural & $9.50(2.59)[4-15]$ & $11.64(2.96)[4-18]$ & $13.00(2.87)[4-19]$ & $13.25(3.06)[4-19]$ \\
Cognitive & $10.13(2.48)[4-15]$ & $12.49(2.62)[4-18]$ & $13.30(2.30)[5-19]$ & $12.81(2.58)[7-19]$ \\
Psychodynamic & $8.04(3.35)[4-18]$ & $9.79(3.72)[4-18]$ & $10.17(3.67)[4-18]$ & $10.93(3.64)[4-19]$ \\
Social realist & $10.89(3.27)[4-18]$ & $12.29(2.79)[4-18]$ & $11.64(2.52)[6-18]$ & $13.06(2.57)[6-18]$ \\
Social constructionist & $8.27(3.23)[4-19]$ & $8.70(3.31)[4-19]$ & $8.93(3.06)[4-17]$ & $10.15(3.38)[4-19]$ \\
Nihilist & $5.97(2.13)[4-13]$ & $6.13(2.07)[4-12]$ & $6.72(2.28)[4-15]$ & $8.06(2.92)[4-19]$ \\
Spiritualist & $6.11(2.35)[4-12]$ & $6.85(2.64)[4-15]$ & $6.71(2.73)[4-15]$ & $7.41(3.05)[4-16]$ \\
\hline
\end{tabular}

Values are given as mean (standard deviation) [range].

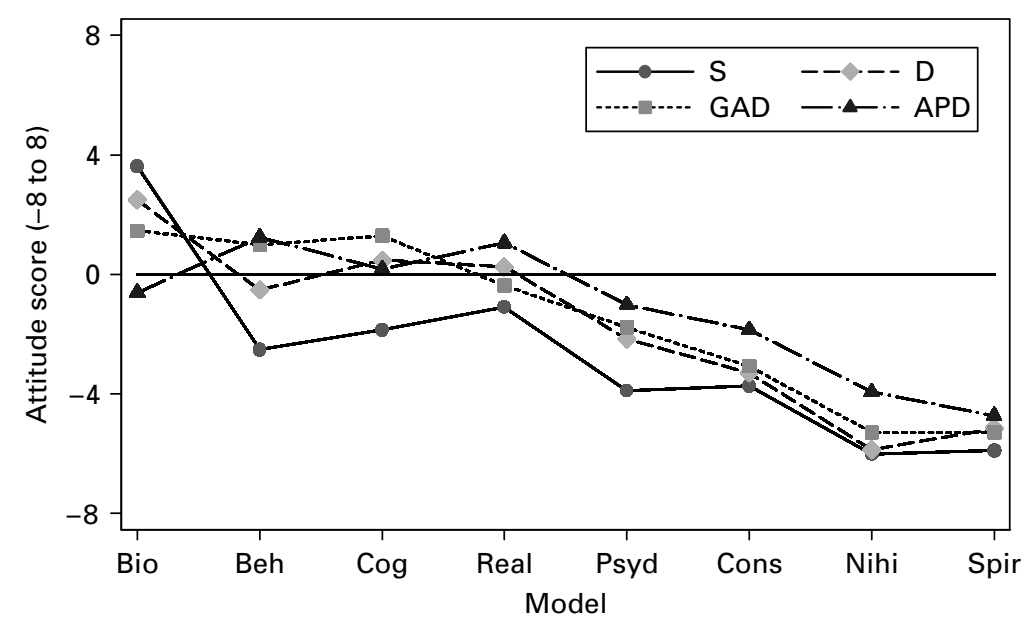

Fig. 1. Standardized mean aggregate attitude scores by model and by disorder (possible range -8 to +8 ). Disorders: APD, antisocial personality disorder; D, depression; GAD, generalized anxiety disorder; S, schizophrenia. Models: Bio, biological; Beh, behavioural ; Cog, cognitive ; Real, social realist; Psyd, psychodynamic ; Cons, social constructionist ; Nihi, nihilist; Spir, spiritualist.

GAD: 'The disorder should be treated by challenging and restructuring maladaptive thoughts and beliefs' [cognitive model, treatment; 62 (82\%)]; and (3) Schizophrenia: 'The appropriate study of the disorder involves discovery of biological markers and the effects of biological interventions' [biological model, research; $61(80 \%)]$.

The three most disagreed-with statements (mean Likert <3) were: (1) Schizophrenia: 'The management of the disorder is best left to the resources of the individual' [nihilist model, treatment; 72 (95\%) of the respondents]; (2) Schizophrenia: 'Attempts to scientifically explain the disorder have resulted in no significant knowledge' [nihilist model, research; 70 (92\%)]; and (3) Schizophrenia: 'Adherence to religious or spiritual practice may lead to the resolution of the disorder' [spiritualist model, treatment; 69 (91\%)].

For all further analysis, individual attitude scores were aggregated to form total attitude scores (range
4-20) for each model and disorder. The means and standard deviations of the aggregate scores by model and disorder are presented in Table 3. Fig. 1 illustrates standardized mean scores (i.e. the mean $=0$ ) to demonstrate the endorsement of each paradigm by disorder more clearly. The $y$ axis indicates attitude score over the four summed questions (aetiology, classification, research and treatment) for each disorder (schizophrenia, MDD, GAD and APD), with the midpoint of 0 corresponding to point 3 (neutral) of the Likert scale. The $x$ axis shows each model category (biological, behavioural, etc.).

Fig. 1 shows that the biological model was most strongly endorsed for schizophrenia; this was followed by MDD, GAD and then APD. For other models, schizophrenia was the least endorsed. The behavioural model was most strongly endorsed for APD and GAD whereas the cognitive model was most strongly endorsed for MDD. Social realist, 
constructionist, psychodynamic, nihilist and spiritualist models were most endorsed for APD, followed by GAD, MDD and lastly schizophrenia. Every disorder had some endorsement (i.e. not strongly disagreed with) by every model. When disregarding the direction of the expressed belief (i.e. agree versus disagree), schizophrenia yielded the greatest strength of belief (mean $=4.16$, s.D. $=1.43$ ), followed by MDD $($ mean $=3.53$, s.D. $=1.43)$, GAD $($ mean $=3.35$, s.D. $=1.18)$ and APD $($ mean $=3.08$, s.D. $=1.09)$.

The formal test for a model $\times$ disorder interaction on endorsement confirmed statistically significant varying of attitude profiles by disorder $\left(\chi^{2}=358, \mathrm{df}=21\right.$, $p<0.0001)$. In other words, model endorsement varied significantly as a function of the disorder.

\section{Dimensions of psychiatrists' attitudes towards mental illness}

The first three PCs extracted from 32 aggregate attitude variables using the PCA accounted for $56 \%$ of the total variance. We considered PCs in this context to be scales or dimensions around which individuals were orientating their attitudes to mental illness. We have only interpreted the first three dimensions because they had the clearest structure. PC1 accounted for 33\% of the total variance and was labelled the 'biological versus non-biological' dimension because it represented the contrast between the biological and all other models, excluding the behaviourist for which the coefficients were neutral. PC2 accounted for a further $12 \%$ of the variance and was labelled the 'biopsycho-spiritual' or 'eclectic' dimension because the coefficients were highest for biological, cognitive, behavioural and spiritual models. PC3 accounted for a further $10 \%$ of the variance and was labelled 'psychodynamic versus sociological' because it represented the contrast between psychodynamic at one end of the scale and social realist, social constructionist and nihilist at the other. (The PCA table with item loadings is available from the authors on request.)

\section{Relationship between dimensions and demographicl professional background variables}

Age was negatively correlated with PC1 $(r=-0.26$, $n=58, p=0.048)$, indicating that as age of the trainees increased so did their tendency to endorse a biological attitude. Years in full-time education correlated negatively with PC1 $(r=-0.25, n=58, p=0.05)$ and PC3 $(r=-0.30, n=58, p=0.02)$, indicating that more educated trainees had a greater tendency to endorse biological and psychodynamic propositions. Religion was significantly associated with PC2 $[F(4,54)=2.78$, $p=0.04]$, with group ratings indicating that Hindus had stronger eclectic attitudes than trainees holding all other religious beliefs.

\section{Discussion}

We carried out a questionnaire survey to investigate trainee psychiatrists' conceptualization of common mental disorders. The questionnaire incorporated propositions derived from major models of mental illness (biological, cognitive, behavioural, psychodynamic and social realist) and also other perspectives on the alterations in experience and behaviour that form the subject matter of psychiatry (social constructivist, nihilist and spiritualist). Repeatedmeasures analysis of variance showed that the level of endorsement of a given model varied with type of disorder. The PCA revealed three underlying dimensions around which psychiatrists organize their attitudes towards mental illness. There were associations between dimensions and demographic variables such as age, years in education, and religious belief.

\section{Demographics and sample characteristics}

The trainees that took part in this study had spent an average of 20 years in education and 5 years in psychiatry. There was a broad representation of religious and political viewpoints, including a significant proportion expressing religious uncertainty $(25 \%$ agnostic) and political disengagement (no political party $34 \%$ ). Twelve per cent had decided on a career in psychiatry before medical school, with the decisions of the rest distributed equally during and after university. Only $3 \%$ of this sample reported being in individual psychoanalysis, and the most common area of research pursued by the sample was in the field of neuroimaging $(20 \%)$. These proportions may be very different in other psychiatric training institutions; for example, the high prevalence of neuroimaging research may reflect opportunities (or encouragement) for this kind of research at the adjacent Institute of Psychiatry. However, despite high levels of selfreported research participation, there was an average of only one (range 0-20) experimental peer-reviewed paper across the sample as a whole, and an absence of published case-study papers. For a sample of trainee psychiatrists, this may partly reflect the length of time taken for research to reach publication.

\section{Single statements}

The three most endorsed single statements in this sample suggest that different models are linked to specific disorders, to the extent that some disorders may be regarded by trainees as paradigmatic exemplars of the explanatory power of a given model; for 
example, that schizophrenia has a biological aetiology and should be investigated through biological research, whereas GAD should be treated by challenging and restructuring maladaptive thoughts and beliefs. Two of the three least endorsed statements derive from the nihilist perspective on schizophrenia and suggest that, as a group, these trainees are particularly confident in their professional knowledge in relation to this disorder.

\section{Aggregated scores}

When the scores across the four questions for each model were aggregated, the above pattern continued, although with some variation. Within the biological model schizophrenia was most strongly endorsed, whereas for all other models it was least so. Within the biological model the psychiatrists' agreement with the model decreased in the order schizophrenia, MDD, GAD and APD. Statements about APD within the biological model recorded an approximately equal level of agreement as the psychoanalytic model. The cognitive model was most endorsed for MDD, whereas the behavioural model was most endorsed for APD and GAD (contrary to what the single statements suggested). Other models (social realist, psychodynamic, social constructionist, nihilist and spiritualist) were most endorsed for APD, followed by GAD and MDD and then schizophrenia. All models received some endorsement for all disorders, including the spiritual model, which was the least endorsed. The $\chi^{2}$ test confirmed that model profiles differed significantly between disorders, with the strongest belief (either agreement or disagreement with propositions from any model) expressed for schizophrenia, followed by MDD, GAD and then APD. In other words, schizophrenia is the disorder that elicits most belief. Hence, our main hypothesis that model endorsement varies with disorder was supported by these findings.

\section{PCA}

The three PCs that we interpreted accounted for 56\% of the total variance. Each main component was classified in terms of its distinctive combination of attitudes from different models: PC1 33\% biological versus non-biological, PC2 12\% eclectic, PC3 10\% psychodynamic versus sociological. The existence of a component indicating a distinction between biological and non-biological items suggests that the biological model is well delineated across disorders (according to the PCA) and most strongly linked to schizophrenia. This may reflect the continuing influence of Kraepelin's 'biological' postulate that psychiatric disorders are caused by an underlying organic pathology, and the linkage of this notion with the disorder
Kraepelin called 'dementia praecox', which Bleuler was later to term 'schizophrenia' (Cutting \& Shepherd, 1987).

By contrast, the 'eclectic' or 'bio-psycho-spiritual' component seems to correspond to a broader analysis of the individual. Being predominantly 'bio-psycho', this approach to thinking about disorders recalls the work of the influential psychiatrist Adolf Meyer and may reflect the persistence of a way of thinking about mental illness originating in his Psychobiology (Meyer, 1957; Lewis, 1967; Kendler, 2008).

The third component reveals an unpredicted contrast between psychodynamic items and sociological ones. This may suggest that when psychiatrists think about disorders in terms other than the biological model or the broader eclectic model, they tend to regard psychodynamic and sociological views as mutually exclusive. This contrast may reflect the differing emphases of psychodynamic and sociological approaches to psychiatric disorders. The psychodynamic approach tends to regard disorders as the product of real but hidden processes located in the individual in response to key relationships (Sandler et al. 1992; Tyrer \& Steinberg, 2005), whereas the sociological approach views 'disorders' as a product of social processes of various kinds (Foucault, 1971; Brown \& Harris, 1978). Hence, the answers of trainee psychiatrists may reflect a tension between two kinds of explanation of behaviour that relate to factors outside of individual awareness and/or control: the psychodynamic and the social. This tension is evident in prior debates about whether 'social' or 'psychodynamic' explanations identify the most fundamental constraints on behaviour; for example, the sociologist and philosopher Ernest Gellner's attempt to explain away psychoanalysis as a social construction (Gellner, 1985), or the debate between Freud's biographer Ernest Jones and the anthropologist Bronislaw Malinowski in the 1920 s as to whether the Oedipus complex is a cultural universal (Bowker, 1973).

Considered together, the three components reveal distinct dimensions around which this group of psychiatrists organized their interpretation of mental disorders. They might be thought of as constituting the group's model or concept of mental illness. Further research is required to determine whether comparable dimensions are present among psychiatrists in other institutional settings and, if so, how these dimensions relate to one another during clinical reasoning and decision making.

\section{Attitudes and demographics}

That more educated trainees may be more likely to hold biological and psychodynamic attitudes could be 
due to the gradual acceptance of attitudes and models prevalent in the teaching and practice of psychiatry. However, it is also possible that biological and psychodynamic attitudes require greater technical expertise, and that those who invest the time and effort to acquire expertise are perhaps more likely to consider the investment as worthwhile; conversely, attitudes such as nihilism may be less age or education dependent.

\section{Comparisons with 1979 (Toone et al. 1979)}

A previous study of trainee psychiatrists' models of mental illness conducted on the same site, but using a different questionnaire and methods, allows for certain specific comparisons. The previous study recorded $25 \%$ as being in individual analysis compared to only $3 \%$ in this study. It suggested that those who were sympathetic to analytic thinking decided to enter psychiatry earlier, were more junior, and had an antipathy to research. This was in opposition to those with a biological or behavioural orientation. In our study we did not find such clear-cut ideological divisions. As discussed above, our results point to the structured use of more than one model by this group of contemporary psychiatric trainees.

\section{Limitations and future work}

This is a pilot study with a relatively small convenience sample from one institution. We recognise that the nature of this sample limits our ability to generalize. To what extent this is representative of the wider profession either in the UK or abroad is not addressed. Future studies using the MAQ in samples from different institutions could provide valuable insights into institution-specific effects on the views and practices of health-care professionals. Another potential limitation is that the use of a questionnaire, and the requirement for formal deliberation on the part of respondents, may capture idealized rather than actual attitudes present in real-world clinical situations. The criterion validity of the current questionnaire could be investigated by the use of qualitative studies of attitudes and decision making in actual clinical situations. In addition, test-retest reliability was not assessed in this study. Future reliability studies need to ensure that psychiatrists' attitudes are measured repeatedly over a time interval that is long enough for the later responses not to be influenced by the earlier responses and short enough for the true attitudes not to have changed.

Because of the limited sample size in the current study, the analysis was based on the assumption that the respondents would endorse the four items within each paradigm on an equal basis. Before creating the aggregate scores, we assessed item correlations within and across paradigms. Although this is not a formal approach to determining internal consistency, we did notice that endorsement of the cognitive treatment item correlated more strongly with the items of other paradigms than with the other items within the cognitive paradigm. This is, perhaps, unsurprising, given that cognitive behavioural therapy (CBT) has become an accepted treatment across disorders even when they are predominantly explained by non-cognitive models (NICE, 2008).

Future studies should aim to confirm empirically the structure and internal consistency of each paradigm as reflected in psychiatrists' attitudes. Specifically, given the appropriate sample size, a factor analysis could be carried out to assess whether the structure of the eight-factor model concurs with the structure of the eight theoretical paradigms and to compare an eight-factor model with models containing fewer underlying factors.

\section{Strengths and implications}

Different models of mental illness within and between mental health-care professions may contribute to the frustration and lack of cohesion felt by professionals and multi-disciplinary teams (Colombo et al. 2003). A first step in addressing this is understanding these differences. Hence, future research into models of mental illness could include junior and senior psychiatrists from the original study site and from other institutions, in addition to other mental health professionals (such as psychologists, social workers and nurses). The present research could also eventually be extended to include service users and the 'lay' public as a basis for identifying potential sources of difference and misunderstanding, and also agreement, between service providers and users (Thornicroft, 2006).

In terms of psychiatry itself, comparative research using the MAQ in other psychiatric training settings may reveal a general effect of psychiatric training, or the influences of different training traditions at specific institutions. The existence of significant institutionspecific effects would raise important questions for training, given that an evidence-based discipline should arguably strive to promote uniformity of perspective and practice among practitioners. Conversely, it could be argued that uniformity of perspective and practice cannot be achieved because psychiatry continues to be substantially underdetermined at the level of both theory and evidence, leading to an inevitable lack of consensus within and between training institutions. It may be that even where consensus seemingly exists (for example, that schizophrenia is 
best understood through the biological model), this may itself represent a cultural lag between the attitudes of clinicians (including trainees) and the evidence base of current research, which, for example, suggests schizophrenia to be a complex multi-factorial disorder with important environmental and social constraints on aetiology (Maccabe et al. 2006). An alternate interpretation is that one of psychiatry's great strengths is that it draws freely on different intellectual disciplines and should therefore be viewed as a 'multi-paradigm' science (Cooper, 2007).

Hence, further research with instruments such as the MAQ may help to measure differences in concepts of mental illness within and between health-care professions. Research into concepts of mental illness may provide a basis for determining to what extent such differences are justified and/or should be addressed in training and service delivery.

\section{Acknowledgements}

This study was supported by a grant from the Institute of Social Psychiatry. We thank Dr Brian Toone for his help with validating the study and Dr Craig Morgan for comments on an earlier draft of this paper.

\section{Note}

Supplementary material accompanies this paper on the Journal's website (http://journals.cambridge.org).

\section{Declaration of Interest}

None.

\section{References}

Bowker J (1973). The Sense of God: Sociological, Anthropological, and Psychological Approaches to the Origin of the Sense of God. Oxford University Press: Oxford.

Brog MA, Guskin KA (1998). Medical students' judgements of mind and brain in the etiology and treatment of psychiatric disorders. Academic Psychiatry 22, 229-235.

Broome MR (2007). Taxonomy and ontology in psychiatry: a survey of recent literature. Philosophy, Psychiatry, and Psychology 13, 303-319.

Brown GW, Harris TO (1978). Social Origins of Depression : A Study of Psychiatric Disorder in Women. Tavistock: London.

Clare AW (1976). Psychiatry in Dissent: Controversial Issues in Thought and Practice. Tavistock: London.

Colombo A, Bendelow G, Fulford B, Williams S (2003). Evaluating the influence of implicit models of mental disorder on processes of shared decision making within community-based multi-disciplinary teams. Social Science and Medicine 56, 1557-1570.

Cooper R (2007). Psychiatry and the Philosophy of Science. Acumen: Chesham.

Cutting J, Shepherd M (eds) (1987). The Clinical Roots of the Schizophrenia Concept. Cambridge University Press: Cambridge.

Deeley Q (2006). The cognitive anthropology of belief. In The Power of Belief (ed. P. Halligan and M. Aylward), pp. 33-54. Oxford University Press: Oxford.

Engel GL (1977). The need for a new medical model: a challenge for biomedicine. Science 196, 129-136.

Foucault M (1971). Madness and Civilization: A History of Insanity in the Age of Reason. Tavistock: London.

Gellner E (1985). The Psychoanalytic Movement. Paladin: London.

Ghaemi N (2003). The Concepts of Psychiatry: A Pluralistic Approach to the Mind and Mental Illness. The Johns Hopkins University Press: Baltimore.

Good B (1995). Medicine, Rationality, and Experience. Cambridge University Press: Cambridge.

Horwitz AV (2002). Creating Mental Illness. Chicago University Press: Chicago.

Kendler KS (2008). Explanatory models for psychiatric illness. American Journal of Psychiatry 165, 695-702.

Kleinman A (1998). The Illness Narratives: Suffering, Healing, and the Human Condition. Basic Books: New York.

Lewis A (1967). The State of Psychiatry: Essays and Addresses. Routledge \& Kegan Paul: London.

MacCabe J, O'Daly O, Murray RM, McGuffin P, Wright P (2006). Beyond Nature and Nurture in Psychiatry. Informa Healthcare: Abingdon, Oxon.

Meyer A (1957). Psychobiology: A Science of Man (ed. E. E. Winters and A. M. Bowers). Charles C. Thomas: Springfield, IL.

Miresco MJ, Kirmayer LJ (2006). The persistence of mind-brain dualism in psychiatric reasoning about clinical scenarios. American Journal of Psychiatry 163, 913-918.

NICE (2008). National Institute for Health and Clinical Excellence NHS Guidelines (http://www.nice.org.uk/ Guidance/CG/Published).

Sandler S, Dare C, Holder A, Dreher AS (1992). The Patient and the Analyst. Karnac Books: London.

Szasz TS (1960). The myth of mental illness. American Psychologist 15, 113-118.

Thomas P, Bracken P (2004). Critical psychiatry in practice. Advances in Psychiatric Treatment 10, 361-370.

Thornicroft GJ (2006). Shunned: Discrimination Against People with Mental Illness. Oxford University Press: Oxford.

Toone BK, Murray R, Clare A, Creed F, Smith A (1979). Psychiatrists models of mental illness and their personal backgrounds. Psychological Medicine 9, 165-178.

Tyrer P, Steinberg D (2005). Models for Mental Disorder: Conceptual Models in Psychiatry. Wiley: Chichester. 